REVIEWS OF DATASETS

Ahmet Izmirlioglu

\title{
From Financial Crash to Debt Crisis
}

Review of: 'From Financial Crash to Debt Crisis'

Author/Compiler: Carmen M. Reinhart and Kenneth S. Rogoff

Repository: www.carmenreinhart.com/data/

Date of Posting: Post-2011

Size: $\geq 4.77 \mathrm{MB}$

Licensing: Creative Commons Public License, CCPL

Volume 2-3, No. 1 (2014-2015) | ISSN 2169-0812 (online)

DOI 10.5195/jwhi.2015.27 | http://jwhi.pitt.edu 
A defining characteristic of world history is its focus on aspects of phenomena that transcend the boundaries of individual political, social, and cultural units - phenomena like migration, trade, ecological change, and their impact on humanity. One of the primary challenges that world historians face, and for which they continue to attract criticism from colleagues, is creating narratives of the human experience that also have explanatory power. ${ }^{1}$ Datasets that simultaneously incorporate both the global and local aspects of large-scale phenomena fortunately provide analytical opportunities to produce such narratives. Correspondingly, the dataset compiled by Carmen M. Reinhart and Kenneth S. Rogoff furnishes researchers in the social sciences and humanities with opportunities to explore the interactions among surprisingly ubiquitous and cyclical phenomena: financial crashes, banking crises, and sovereign debt defaults. ${ }^{2}$

The dataset consists of time series data related to the above cyclical phenomena in 221 countries and regions, reaching back when possible to 1800 or earlier, and updated to as late as 2010. The data include dates for banking crises, currency crashes, sovereign domestic or external default, inflation crises, as well as pertinent rates such as debt to GDP ratios, among many others. The authors compiled the dataset from the works of numerous scholars, data published by international organizations such as the World Bank and the IMF, as well as country-specific official sources.

Individual data files can be browsed by topic or country, making it easy to distinguish between global and individual country data. For instance, one may find official and parallel exchange rates for countries from 1946 to 1998 presented in the topic titled "Exchange Rates (Official and Parallel)," so that one can compare the exchange rates of any listed country in a given month within this period. But additionally, one finds a chronology of the exchange rate regimes adopted by each country within this period under the topic "Updated Country Chronologies (1946:1-2007:12)," so that one can also see indications of local economic and political factors that shaped the exchange rates of each country. ${ }^{3}$

The topics are presented under the two categories, This Time is Different (related to the identically named book, with topics such as "Debt-to-GDP Ratios" and "Bond Issuance (debentures)," and "Other Data Topics" (with topics such as "Capital Flow Bonanzas" and "Twin Crises." The data require only a basic familiarity with economics terminology and the authors provide plenty of assistance by supplying relevant definitions in the individual documents (usually in separate tabs within the same file). However, the naming conventions used by the authors for the MS Excel and MS Word files are somewhat unfriendly. For instance, a link titled "Figure 6.1" under the topic "Updated Country Chronologies (1946:1-2007:12)" leads one to a document with the graph of Spanish defaults and loans to the crown from 1601-1679. Yet the title of the MS Excel file containing the graph is "151_data.xlsx," thus providing no indication of its contents and forcing one to rename the document for a useful classification.

The authors used this dataset in an influential (and controversial) paper published in 2011, which is worth mentioning briefly as an introduction to the dataset and its possible uses. ${ }^{4}$ Reinhart and Rogoff used historical time series on public debt and modern data on external debts to analyze cycles of debt and banking crises over the past two centuries. The analysis, based on both cross-country aggregates and individual country histories, suggested a strong connection between debt cycles and economic crises. Specifically, the authors concluded that banking crises in global financial centers may help explain domestic banking crises, which in turn may help explain sovereign debt default. ${ }^{5}$ Findings that led the authors to these conclusions included such factors as surges in public debts ahead of sovereign debt crises and similar rises in private debts preceding banking crises. Although the causal direction 
between banking and debt crises, as modeled in the paper, ran in either or both directions, individual country histories suggested a prevalence of banking crises preceding debt crises.

Importantly, these findings depend on the specific quantitative model and set of assumptions selected by the authors. Researchers aiming to expand on Reinhart and Rogoff's work by using this dataset, for quantitative or qualitative research, or supplementing it with their own data, should carefully consider the implications of these assumptions for their own models. The quantitative model in the paper is a modified vector autoregression (VAR) that used the logit function to determine temporal precedence between the endogenous variables: the variables that are calculated solely based on their lagged values-banking crisis (BC) and debt crisis (DC). The model also includes an exogenous variable-financial crisis in a global financial center (FC) - that distinguishes between the countries labeled as advanced or emerging markets. In simple terms, the model alternately treated banking and debt crises as dependent variables, testing to see whether interactions among the past values of the dependent variable and the other variables increased the likelihood of the occurrence of the dependent variable. The authors ran simulations with numerous variations to the model to account for structural anomalies natural to data spanning two centuries. These variations included replacement of the logit function with ordinary least squares (OLS) and OLS with robust errors, as well as introduction of new variables (for example, a debt/GDP measure). The results of the variations remained consistent with the original results.

Researchers need not employ such sophisticated quantitative models to utilize this dataset. Indeed, Reinhart and Rogoff's conclusions suggest that banking crises are strong indicators of sovereign debt defaults, but not necessarily predictors of such defaults. Furthermore, as the authors themselves hint, a strictly economics-based approach alone cannot explain the complex factors behind these phenomena. ${ }^{6}$ The dataset, then, provides an invitation to multidisciplinary research that suggests explanations of these complex phenomena using the deep social, cultural, political, and psychological factors that lie beneath. At the least, researchers may find points of entry to interesting problems in their own fields that coincide with the geographic or temporal points of crises outlined in the dataset. But the dataset is wealthy enough to support far more sophisticated efforts.

\section{NOTES}

${ }^{1}$ For a recent criticism aimed at "global" history, see David Bell, "This Is What Happens When Historians Overuse the Idea of the Network," New Republic, http://www.newrepublic.com/article/114709/world-connectingreviewed-historians-overuse-network-metaphor, October 23, 2013 (Accessed on August 4, 2015).

${ }^{2}$ The entire dataset is available at http://www.carmenreinhart.com/data/. The portion of the dataset strictly pertaining to Reinhart and Rogoff's paper titled "From Financial Crash to Debt Crisis" is located at https://www.aeaweb.org/aer/data/aug2011/20080344_data.zip.

${ }^{3}$ The links in the "Browse by Country" and "Browse by Topic" sections both point to the same MS Excel and MS Word files. However, individual country data is easy to identify in clearly organized spreadsheet columns or text document sections in each case.

${ }^{4}$ Carmen Reinhart and Kenneth Rogoff, "From Financial Crash to Debt Crisis," The American Economic Review 101, no. 5 (August 2011): 1676-1706. The dataset also contains some data used in subsequent works by the authors. 
${ }^{5}$ The authors found no direct link between crises in global financial centers and sovereign debt crises.

${ }^{6}$ Reinhart and Rogoff, "From Financial Crash to Debt Crisis," 1692-3, 1697.

(c) $\mathbf{E Y}_{\mathrm{EY}}$ Articles in this journal are licensed under a Creative Commons Attribution 4.0 United States License.

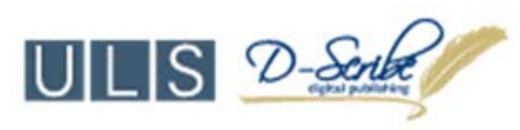

This journal is published by the University Library System of the University of Pittsburgh as part of its D-Scribe Digital Publishing Program and is cosponsored by the University of Pittsburgh Press. 